\title{
PHYSICAL ACTIVITY AS A DETERMINANT OF SUBJECTIVE HAPPINESS
}

\author{
Ceyhun Alemdag, Serdar Alemdag, Abdullah Bora Ozkara \\ Karadeniz Technical University, Trabzon, Turkey
}

\begin{abstract}
Background. It is clear that happiness is the aim for individuals living in a highly demanding society. Although much behaviour may result in perceived subjective happiness, it is thought that physical activity is one of such factors. In this respect, the aim of this study was to investigate participants' subjective happiness as a result of their level of the amount of exercise they take part in, as well as other secondary measures (gender, body mass index, sports facilities and sports participation of family members).

Methods. The study sample consists of 312 undergraduate students (114 females, 198 males). Exercise Stages of Change Questionnaire (ESOCQ) and Subjective Happiness Scale (SHS) were used as a data collection tool in the study. Data was analyzed using the one-way analysis of variance (ANOVA), Kruskal-Wallis H test, T-test and ChiSquare $\left(\chi^{2}\right)$ test.

Results. The results indicated that subjective happiness of undergraduate students was dependant on how physically active they were, particular in males, with normal body mass index and also those who were members of sporting facilities and whose parents were also physically active.

Conclusion. This study showed that university students who participated in physical activity showed subjectively higher levels of perceived happiness. Furthermore, the factors determining these relationships were supported by gender, body mass index, sports facilities and whether or not their close family members were also physically active.
\end{abstract}

Keywords: exercise, wellbeing, university students.

\section{INTRODUCTION}

$\mathrm{T}$ here has been an increase in the number of research focusing on positive emotions and experiences with the development of positive psychology in the second half of the $20^{\text {th }}$ century (Gillham \& Seligman, 1999; Seligman, 2003). Such research especially has addressed topics of subjective well-being, happiness and life satisfaction (Myers \& Diener, 1995). Thus, happiness has been the subject of many research disciplines, primarily biology and psychology; inquiries into happiness can be traced back to ancient history philosophers (Aristotle, Democritus, etc.) (Angner, 2010; Diener, 2000; Hills \& Argyle, 2002; Lane, Reiman, Ahern, Schwartz, \& Davidson, 1997; Seligman \& Csıkszentmihaly1, 2000; Sin \& Lyubomirsky, 2009; Taylor \& Brown, 1988).
Happiness involves positive emotions, negative emotions and life satisfaction. The positive affective dimension of happiness involves emotions such as joy, excitement and confidence while the negative affective dimension includes emotions such as guilt, sadness, anger and hatred. The life satisfaction dimension consists of an individual's assessments of satisfaction in various areas of life (Myers \& Diener, 1995). When examined, physical activity (PA) appears to be closely associated with all these items of positive and negative emotions. This association may be either in the form of reducing the level of negative emotions (depression, anxiety and anger) (Arslan, Güllü, \& Tutal, 2011; A. Byrne \& D. G. Byrne, 1993; Cameron \& Hudson, 1986; Folkins \& Sime, 1981; Fremont \& Craighead, 
1987) or may emerge in the form of increasing the level of positive emotions (happiness, etc.) (Chyi \& Mao, 2012; Ferrer-i-Carbonell \& Frijters, 2004). Although there are a number of studies that examine the relationship between PA and happiness in the literature (Bloodworth, McNamee, \& Bailey, 2012; Fox, 1999; Gauvin \& Spence, 1996; Hassmen, Koivula, \& Uutela, 2000; Huang \& Humphreys, 2012; McAuley et al., 2000; Netz, Wu, Becker, \& Tenenbaum, 2005), such studies are very rare in Turkey (Cartel, Bahadır, Saracaloğlu, \& Varol, 2015; Yalız Solmaz, 2014). Hence, the purpose of this study is to investigate university students' level of subjective happiness in terms of participation in PA. To this end, answers were sought the following questions:

1. Does students' level of subjective happiness significantly differ by stages of exercise behaviour?

2. Does students' level of subjective happiness and stages of exercise behaviour significantly differ according to gender, body mass index, sports facilities and sports participation of family members?

\section{METHODS}

The study adopted cross-sectional design and self-reported questionnaires were used to collect data.

Participants. The study sample consists of 312 undergraduate students (114 females, 198 males) from Karadeniz Technical University (KTU) who completed a questionnaire package that included Exercise Stages of Change Questionnaire (ESOCQ) and Subjective Happiness Scale (SHS). The study was carried out in 2015-2016 academic year in Trabzon.

Procedure. Following the approval of the study by KTU, the authors contacted with the instructors of each selected faculty for he convenient time to apply the questionnaire. Questionnaires were administrated before or at the end of the lesson. Before applying the questionnaire, participants were informed about the study, and their informed consents were taken. Then, completed questionnaires were returned to the authors.

Instruments. Exercise Stages of Change Questionnaire (ESOCQ). ESOCQ is a four-item measure which was developed by Marcus and Lewis (2003) to determine the stage of exercise behaviour of an individual. ESOCQ is a binary type (yes/no) questionnaire. Participants answer each question related to their PA participation as "yes" or "no". Based on their responses, they were classified into five different stages by using a scoring algorithm. Specifically, the stages include Pre-contemplation, Contemplation, Preparation, Action, and Maintenance. Among them, precontemplators and contemplators are physically inactive/passive, preparers are physically active but not at the recommended levels and individuals in the action and maintenance stages are physically active. ESOCQ has been translated from English to Turkish and psychometric properties have been examined by Cengiz, Aşçı and İnce (2010). In the Turkish version of ESOCQ the level of PA (low, moderate, and high) were tested among the participants at five different exercise stages. Analyses demonstrated significant differences in the PA level in terms of exercise stages. Analysis also indicated adequate test-retest reliability based on two weeks' interval (ICC $=.80$ ). In this study, Turkish version of the ESOCQ was used for the Turkish students.

Subjective Happiness Scale (SHS). The Subjective Happiness Scale is a scale developed to evaluate the global subjective happiness. SHS is a 7-point Likert type self-report style measurement tool. The scale consists of 4 items. Lyubomirsky and Lepper (1999) have reported that the internal consistency of SHS varies between .79 and .94 for samples consisting of different ages, cultures, languages and professions. SHS has been translated from English to Turkish and psychometric properties examined by Doğan and Totan (2013). The Turkish version of the SHS was used in this study.

Statistical analysis. The data was analysed using the Statistical Package for Social Sciences (SPSS) version 21.0. The one-way analysis of variance (ANOVA), Kruskal-Wallis and T-test were used to determine whether there were any significant differences between the means of independent/unrelated groups. Additionally, ChiSquare $\left(\chi^{2}\right)$ test was used to determine whether there was a relationship between categorical variables.

\section{RESULTS}

According to the results of the $\chi^{2}$ test for one sample shown in Table 1a, most of the participants were in the active stage of exercise behaviour 
(40.4\%), and least of the participants were in the preparation stage of exercise behaviour (23.4\%). The results of $\chi^{2}$ test indicated that there was statistically significant relationship between stages of exercise behaviour, $\chi^{2}(2, n=312)=14.67, p<.01$.

Table 1a. The distribution of stages of exercise behaviour

\begin{tabular}{|l|c|c|}
\hline \multicolumn{1}{|c|}{ Stage of Exercise Behaviour } & $\boldsymbol{n}$ & $\mathbf{\%}$ \\
\hline Passive & 113 & 36.2 \\
\hline Preparation & 73 & 23.4 \\
\hline Active & 126 & 40.4 \\
\hline Total & 312 & 100 \\
\hline
\end{tabular}

Note. $\chi^{2}=14.67, d f=2, p=.001$.

Table 1b. The distribution of SHS scores according to stages of exercise behaviour

\begin{tabular}{|l|c|c|c|c|}
\hline & $\begin{array}{c}\text { Passive } \\
(\boldsymbol{n}=\mathbf{1 1 3}) \\
(\boldsymbol{M} \pm \boldsymbol{S D})\end{array}$ & $\begin{array}{c}\text { Preparation } \\
(\boldsymbol{n}=\mathbf{7 3}) \\
(\boldsymbol{M} \pm \boldsymbol{S D})\end{array}$ & $\begin{array}{c}\text { Active } \\
(\boldsymbol{n}=\mathbf{1 2 6}) \\
(\boldsymbol{M} \pm \boldsymbol{S D})\end{array}$ & $\boldsymbol{p}$ \\
\hline $\begin{array}{l}\text { Subjective } \\
\text { Happiness }\end{array}$ & $4.19 \pm 1$ & $4.54 \pm 1.1$ & $5.71 \pm 0.7$ & .000 \\
\hline
\end{tabular}

Note. $(M \pm S D)-$ Mean and Standard Deviation.

Table $1 \mathrm{~b}$ shows the results based on Analysis of Variance (ANOVA) between stages of exercise behaviour and students' subjective happiness. The results suggested that the stage of exercise was significantly associated with students' subjective happiness, $F(2,309)=84.18, p<.01$. Post-hoc analysis using Tukey method showed that passive stage students $(4.19 \pm 1)$ were significantly different from preparation stage $(4.54 \pm 1.1, p=.038)$ and active stage students $(5.71 \pm 0.7, p=.000)$, and also preparation stage students $(4.54 \pm 1.1)$ were significantly different from active stage students (5.71 $\pm 0.7, p=.000)$ in relations to students' subjective happiness.

Table 2a shows the results of the $\chi^{2}$ test on whether students' level of exercise behaviour was associated with gender. Considering Table 2a, nearly half of the male students were in the active stage of exercise behaviour, while the majority of the female students were in the passive stage of exercise behaviour. The results of $\chi^{2}$ test indicated that there was statistically significant relationship between stages of exercise behaviour and gender, $\chi^{2}(2, n=312)=7.38, p<.05$. In other words, there was a statistically significant relation between students' exercise behaviour and gender.

Students' subjective happiness scores by gender are shown in Table $2 \mathrm{~b}$. The analysis of the subjective happiness of the students showed that there were no significant differences between female $(\mathrm{M}=4.8 \pm 1.2)$ and male $(\mathrm{M}=4.93 \pm 1.14)$ students $(t(310)=-.95, p>.05)$.

Table $3 \mathrm{a}$ shows the results of the $\chi^{2}$ test on whether students' level of exercise behaviour was associated with BMI. Based on the rates, the majority of students in the obese category $(60 \%)$ were in the preparation stage of exercise behaviour. Overweight students were mostly in the passive stage of exercise behaviour, while underweight and healthy students were in the active stage of exercise behaviour ( $42.1 \%$ and $45.9 \%$, respectively). The results of $\chi^{2}$ test revealed that there was statistically significant difference between the stages of exercise behaviour and BMI, $\chi^{2}(6, n=312)=20.28, p<.01$.

According to the BMI of the students, Kruskal-Wallis $H$, taken from SHS scores, was given in Table 3b. Analysis showed that there was a statistically significant differences between
Table $2 \mathrm{a}$. The distribution of stages of exercise behaviour by gender

Note. $\chi^{2}=7.38, d f=2, p=.025$.

Table 2b. The distribution of SHS scores according to gen

Note. $M=$ Mean; $S D=$ Standard Deviation.

\begin{tabular}{|c|c|c|c|c|c|}
\hline \multirow{2}{*}{ Gender } & \multirow{2}{*}{$\boldsymbol{n ( \% )}$} & \multicolumn{3}{|c|}{ Stages of Exercise Behaviour } & \multirow{2}{*}{ Total } \\
\cline { 3 - 6 } & & Passive & Preparation & Active & \\
\hline Female & $n(\%)$ & $46(40.4)$ & $33(28.9)$ & $35(30.7)$ & $114(100)$ \\
\hline Male & $n(\%)$ & $67(33.8)$ & $40(20.2)$ & $91(46.0)$ & $198(100)$ \\
\hline Total & $n(\%)$ & $113(36.2)$ & $73(23.4)$ & $126(40.4)$ & $312(100)$ \\
\hline
\end{tabular}

\begin{tabular}{|l|c|c|c|c|c|c|c|}
\hline & Gender & $\boldsymbol{n}$ & $\boldsymbol{M}$ & $\boldsymbol{S D}$ & $\boldsymbol{d f}$ & $\boldsymbol{t}$ & $\boldsymbol{p}$ \\
\hline \multirow{2}{*}{$\begin{array}{l}\text { Subjective } \\
\text { Happiness }\end{array}$} & Female & 114 & 4.8 & 1.2 & & & \\
\cline { 1 - 8 } & Male & 198 & 4.93 & 1.14 & & -.95 & .342 \\
\hline
\end{tabular}




\begin{tabular}{|l|c|c|c|c|c|}
\hline \multirow{2}{*}{ BMI $\left(\mathbf{k g} \cdot \mathbf{m}^{-2}\right)$} & \multirow{2}{*}{$\boldsymbol{n ( \% )}$} & \multicolumn{3}{|c|}{ Stages of Exercise Behaviour } & \multirow{2}{*}{ Total } \\
\cline { 3 - 5 } & & Passive & Preparation & Active & \\
\hline Underweight & $n(\%)$ & $6(31.6)$ & $5(26.3)$ & $8(42.1)$ & $19(100)$ \\
\hline Healthy & $n(\%)$ & $76(34.5)$ & $43(19.5)$ & $101(45.9)$ & $220(100)$ \\
\hline Overweight & $n(\%)$ & $27(46.6)$ & $16(27.6)$ & $15(25.9)$ & $58(100)$ \\
\hline Obese & $n(\%)$ & $4(26.7)$ & $9(60.0)$ & $2(13.3)$ & $15(100)$ \\
\hline Total & $n(\%)$ & $113(36.2)$ & $73(23.4)$ & $126(40.4)$ & $312(100)$ \\
\hline
\end{tabular}

Table 3a. The distribution of stages of exercise behaviour by BMI

\begin{tabular}{|c|c|c|c|c|c|}
\hline BMI & $\boldsymbol{n}$ & Mean Rank & df & $\chi^{2}$ & $\boldsymbol{p}$ \\
\cline { 1 - 3 } Underweight & 19 & 152.58 & & & \\
\cline { 1 - 3 } Healthy & 220 & 167.23 & \multirow{2}{*}{3} & 12.12 & .007 \\
\cline { 1 - 3 } Overweight & 58 & 126.76 & & & \\
\hline Obese & 15 & 119.03 & & & \\
\hline
\end{tabular}

Note. $\chi^{2}=20.28, d f=6, p=.002$, (BMI) - Body Mass Index.

\begin{tabular}{|c|c|c|c|c|c|}
\hline \multirow{2}{*}{$\begin{array}{c}\text { Sports } \\
\text { Facilities }\end{array}$} & \multirow{2}{*}{$\boldsymbol{n ( \% )}$} & \multicolumn{3}{|c|}{ Stages of Exercise Behaviour } & \multirow{2}{*}{ Total } \\
\cline { 3 - 5 } & & Passive & Preparation & Active & \\
\hline Yes & $n(\%)$ & $75(32.2)$ & $51(21.9)$ & $107(45.9)$ & $233(100)$ \\
\hline No & $n(\%)$ & $38(48.1)$ & $22(27.8)$ & $19(24.1)$ & $79(100)$ \\
\hline Total & $n(\%)$ & $113(36.2)$ & $73(23.4)$ & $126(40.4)$ & $312(100)$ \\
\hline
\end{tabular}

Table $3 \mathrm{~b}$. The distribution of SHS scores according to BMI

Note. (BMI) - Body Mass Index.

\begin{tabular}{|l|c|c|c|c|c|c|c|}
\hline & $\begin{array}{c}\text { Sports } \\
\text { Facilities }\end{array}$ & $\boldsymbol{n}$ & $\boldsymbol{M}$ & $\boldsymbol{S D}$ & $\boldsymbol{d f}$ & $\boldsymbol{t}$ & $\boldsymbol{p}$ \\
\hline \multirow{2}{*}{$\begin{array}{l}\text { Subjective } \\
\text { Happiness }\end{array}$} & Yes & 233 & 5.04 & 1.14 & \multirow{2}{*}{310} & \multirow{2}{*}{4.24} & .000 \\
\cline { 1 - 8 } & No & 79 & 4.42 & 1.13 & & \\
\hline
\end{tabular}

Table 4a. The distribution of stages of exercise behaviour by sports facilities

Note. $\chi^{2}=12.01, d f=2, p=.002$.

subjective happiness by BMI types, $\chi^{2}(3)=12.12$, $p<.01$. This finding indicates that the BMI showed different effects on the subjective happiness of the students. Considering the mean rank of the groups, healthy students had the highest scores in subjective happiness, which was followed by underweight, overweight and obese students.

The data were obtained from students who had and did not have sports facilities (Table 4a). As seen in Table $4 \mathrm{a}$, the rate of the students in the active stage of exercise behaviour was $45.9 \%$ within the group with sports facilities, while it was $24.1 \%$ within the group without sports facilities. Students who did not have sports facilities were mostly in the passive stage of exercise behaviour.
The results of $\chi^{2}$ test revealed that there was statistically significant difference between the stages of exercise behaviour and sports facilities, $\chi^{2}(2, n=312)=12.01, p<.01$. Thus, there was a significant relation between sports facilities and stages of exercise behaviour.

Students' subjective happiness scores by sports facilities are shown in Table 4b. The analysis of students' subjective happiness indicated that there was a statistically significant difference between students who had and did not have sports facilities, $t(310)=4.24, p<.01$. The mean subjective happiness score of the students with sports facilities $(M=5 \pm$ 1.1) were higher than the mean subjective happiness score of those without sports facilities ( $\mathrm{M}=$ $4.4 \pm 1.1)$. 


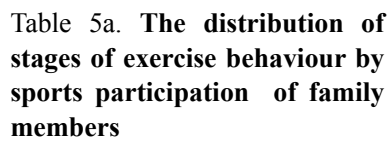

Note. $\chi^{2}=31.9, d f=2, p=.000$.

\begin{tabular}{|c|c|c|c|c|c|}
\hline \multirow{2}{*}{$\begin{array}{c}\text { Sports } \\
\text { Participation of } \\
\text { Family Members }\end{array}$} & \multirow{n}{*}{$(\%)$} & \multicolumn{3}{|c|}{ Stages of Exercise Behaviour } & \multirow{2}{*}{ Total } \\
\cline { 3 - 5 } & & Passive & Preparation & Active & \\
\hline Yes & $n(\%)$ & $25(19.8)$ & $28(22.2)$ & $73(57.9)$ & $126(100)$ \\
\hline No & $n(\%)$ & $88(47.3)$ & $45(24.2)$ & $53(28.5)$ & $186(100)$ \\
\hline Total & $n(\%)$ & $113(36.2)$ & $73(23.4)$ & $126(40.4)$ & $312(100)$ \\
\hline
\end{tabular}

\begin{tabular}{|c|c|c|c|c|c|c|c|}
\hline & $\begin{array}{l}\text { Sports Participation } \\
\text { of Family Members }\end{array}$ & $n$ & $M$ & $S D$ & $d f$ & $t$ & $p$ \\
\hline \multirow{2}{*}{$\begin{array}{l}\text { Subjective } \\
\text { Happiness }\end{array}$} & Yes & 126 & 5.23 & 1.08 & \multirow{2}{*}{310} & \multirow{2}{*}{4.4} & \multirow{2}{*}{.000} \\
\hline & No & 186 & 4.65 & 1.16 & & & \\
\hline
\end{tabular}

Table $5 b$. The distribution of SHS scores according to sports participation of family members

Note. $M=$ Mean; $S D=$ Standard Deviation. individuals' levels of positive psychology (Biddle, Fox, \& Boutcher, 2003; Weinberg \& Gould, 2014). The relationship between participation in PA and subjective happiness levels of individuals has been the subject of study in almost every age group, and such studies have found out that participation in PA positively contributes to subjective happiness/ subjective well-being levels of individuals (Cartel et al., 2015; Fox, 1999; Holder, Coleman, \& Sehn, 2009; Huang \& Humphreys, 2012; McAuley et al., 2000; Netz et al., 2005; Ruseski, Humphreys, Hallman, Wicker, \& Breuer, 2014; Stathi, Fox, \& McKenna, 2002; Stubbe, De Moor, Boomsma, \& De Geus, 2007; Yalız Solmaz, 2014). The findings of the present study appear to be in parallel with the literature with respect to participation in PA and subjective happiness level.

Considering the relationship between stages of exercise behaviour of university students and gender, the rate of male students was higher in the active stage of exercise behaviour while the rate of female students was higher in the preparation and passive stages (Table 2a). In a large-scale study examining participation in PA by gender in a group of 1032 participants (53\% women and $47 \%$ of men) with mean age 47.3 years (Lissitsa, Galily, \& Chachashvili-Bololotin, 2010), men were more physically active and exhibited positive attitudes towards sports while women were more physically inactive and displayed neutral or negative attitudes. A study examining PA among young people similarly reported that men were more physically active than women (Trost et al., 2002). In another study on leisure time physical activities (Ainsworth, Richardson, Jacobs Jr, \& Leon, 1993), the intensity of PA was higher in men. Comparing subjective Studies indicate that sports and PA contribute to 
happiness by gender, this study has found that although subjective happiness scores of male students are higher than those of female students, this difference is not statistically significant (Table 2b). In a similar way to this study, several studies in the literature also have reported that there is no significant difference between women and men in terms of happiness (Francis, 1998; Kousha \& Mohseni, 2000; Mahon, Yarcheski, \& Yarcheski, 2005). Huang and Humphreys (2012) suggest that both men and women experienced happiness when they participated in physical activity, and men seemed to benefit more. In the present study, men have a higher level of subjective happiness than women; however, the difference between the means is not significant. Thus, the findings of the present study seem to be in parallel with those of other studies examining physical activity and happiness with respect to gender.

In this study, most of the students under the categories of underweight and healthy were found to be active stage of exercise behaviour. In addition, students under the category of overweight were mostly passive while students under the category of obese were at the preparation stage of exercise behaviour (Table 3a). In a study examining the impact of some factors on BMI (Taylor, Jatulis, Winkleby, Rockhill, \& Kraemer, 1994), individuals' BMI-slopes were found to be lower with increased PA. In a similar vein, in a study conducted on 1213 black and 1166 white girls in the USA (Kimm et al., 2005), changes in activity levels of adolescent girls significantly influenced changes in BMI and adiposity. The findings of the present study seem to be similar to those of other studies in the literature on the association between participation in PA and BMI. In the study on PA and BMI, Herman, Craig, Gauvin and Katzmarzyk (2009) stated that "The majority of overweight youth remained overweight as adults; however, the majority of overweight adults were not overweight youth" (p. 281). Based on this conclusion, the present study may highlight the importance of maintaining their state in the following years of their life for university students who are physically active and under the healthy category of BMI. When subjective happiness is compared by BMI in the present study, subjective happiness scores of healthy students are higher than those of underweight, overweight and obese students (Table 3b). Headey, Muffels and Wagner (2010) reported that underweight men had lower life satisfaction and obese women were relatively unhappy. In their study conducted in 2007, Oswald and Powdthavee presented clear evidence that happiness and mental health were worse among fatter British and German people. Blanchflower and Oswald (2011) similarly argued that happy individuals were slimmer. Based on the literature findings, it is safe to say that healthy students generally participate in more physical activity and feel happier. Examining BMI in terms of participation in physical activity and subjective happiness, the present study concluded similar results to previous studies.

Considering the availability of sports facilities, students who had sports facilities in their surroundings participated in sports more actively. In other words, students who did not have sports facilities in their surroundings were found to be rather in the passive and preparation stages of exercise behaviour (Table 4a). Huang and Humphreys (2012) noted that those who had access to sports facilities were more likely to participate in PA. Provision of an exercise environment was also found to maximize the possibility to participate in PA (McAuley et al., 2000). In a study examining genetic and environmental factors in sports participation of male and female twins, environmental factors affected sports participation in young adolescence but stopped to be important in adulthood because of genetic factors (Stubbe, Boomsma, \& De Geus, 2005). The present study examined sports facilities with respect to both stages of exercise behavior and subjective happiness. Based on the analysis results, the students with sports facilities have higher scores of subjective happiness than those without sports facilities (Table 4b). Huang and Humphreys (2012) argue that more sports facilities lead to higher happiness. As indicated by a previous study, for older adults, exercise environment is a significant determinant of subjective well-being (McAuley et al., 2000). Thus, it seems that there is an association between sports facilities and happiness. In the present study, sports facilities are of importance for both stages of exercise behaviour and subjective happiness.

Another focus of this study is the importance of parental modelling in young people's participation in sports and PA. Cote (1999) indicated that parents' participation in sports could be taken as a model by children, and further noted that the role of the family in youth's participation in sports was a complex phenomenon because of the diversity of family context. In this study, the assessment of 
sports participation of family members revealed that students whose family members participated in sports also participated in sports more actively (nearly 60\%). Students whose family members did not participate in sports were found to be in the passive stage of exercise behaviour (Table 5a). A number of studies indicated that family served as a role model in girls' participation in PA and sports (Colley, Eglington, \& Elliot, 1992; Gregson \& Colley, 1986). Another study that examined the impact of parents on Chinese children's PA highlighted the importance of parental role modelling (Lijuan, Jiancui, \& Suzhe, 2016). In a study focusing on parental perceptions about the importance of children's participation in PA, physically active parents emphasised the importance of children's participation in PA more than physically inactive parents (Hein, 2015). When students' subjective happiness is analysed in terms of sports participation of family members, students whose family members participate in sports have a higher level of subjective happiness than those whose family members do not participate in sports (Table 5b). Taking into consideration that nearly $60 \%$ of students whose family members participate in sports are in the active stage of exercise behaviour, sports participation of family members seems to be associated with students' subjective happiness.

\section{CONCLUSION}

All in all, the present study has two important results. Firstly, university students who show active participation in physical activity have a higher level of subjective happiness; and secondly gender, body mass index, sports facilities and sports participation of family members except for gender are determinants of university students' participation in physical activity and subjective happiness. Further studies can examine the association between students' stages of exercise behaviour and subjective happiness in different age groups. Students' stages of exercise behaviour and subjective happiness can also be analysed in a longitudinal study.

\section{REFERENCES}

Ainsworth, B. E., Richardson, M., Jacobs Jr, D. R., \& Leon, A. S. (1993). Gender differences in physical activity. Women in Sport \& Physical Activity Journal, 2(1), 1.

Angner, E. (2010). Subjective well-being. The Journal of Socio-Economics, 39(3), 361-368.

Arslan, C., Güllü, M., \& Tutal, V. (2011). Analysing the depression states of elementary school students who do sports or not according to some variables. Nigde University Journal of Physical Education and Sport Sciences, 5(2), 120-132.

Biddle, S. J., Fox, K., \& Boutcher, S. (Eds.). (2003). Physical activity and psychological well-being. Routledge.

Blanchflower, D. G., \& Oswald,A. J. (2011). International happiness: A new view on the measure of performance. The Academy of Management Perspectives, 25(1), 6-22.

Bloodworth, A., McNamee, M., \& Bailey, R. (2012). Sport, physical activity and well-being: An objectivist account. Sport, Education and Society, 17(4), 497-514. http://dx.doi.org/10.1080/13573322.2011.608948

Byrne, A., \& Byrne, D. G. (1993). The effect of exercise on depression, anxiety and other mood states: A review. Journal of Psychosomatic Research, 37(6), 565-574.

Cameron, O. G., \& Hudson, C. J. (1986). Influence of exercise on anxiety level in patients with anxiety disorders. Psychosomatics, 27(10), 720-723.
Cartel, Z., Bahadır, Z., Saracaloğlu, S., \& Varol, R. (2015). The investigation of the relation between the high school students' self-efficacy and subjective wellbeing. Journal of Research in Education and Teaching, 4(2), 307-318.

Cengiz, C., Aşçı, F. H., \& İnce, M. L. (2010). "Exercise Stages of Change Questionnaire": Its reliability and validity. Turkiye Klinikleri Journal of Sports Sciences, 2(1), 32-37.

Chyi, H., \& Mao, S. (2012). The determinants of happiness of China's elderly population. Journal of Happiness Studies, 13(1), 167-185. doi: 10.1007/ s10902-011-9256-8

Colley, A., Elington, E., \& Elliott, E. (1992). Sport participation in middle childhood: Association with styles of play and parental participation. International Journal of Sport Psychology, 23(3), 193-206.

Cote, J. (1999). The influence of the family in the development of talent in sport. The Sport Psychologist, 13(4), 395-417.

Diener, E. (2000). Subjective well-being: The science of happiness and a proposal for a national index. American Psychologist, 55(1), 34-43. doi: 10.1037/0003066X.55.1

Doğan, T., \& Totan, T. (2013). Psychometric properties of Turkish version of the Subjective Happiness Scale. The Journal of Happiness and Well-Being, 1(1), 20-27. 
Ferrer-i-Carbonell, A., \& Frijters, P. (2004). How important is methodology for the estimates of the determinants of happiness? The Economic Journal, 114(497), 641-659. doi: 10.1111/j.1468-0297.2004.00235.x

Folkins, C. H., \& Sime, W. E. (1981). Physical fitness training and mental health. American Psychologist, $36(4), 373$.

Fox, K. R. (1999). The influence of physical activity on mental well-being. Public Health Nutrition, 2(3a), 411-418.

Francis, L. J. (1998). Happiness is a thing called stable extraversion: A further examination of the relationship between the Oxford Happiness Inventory and Eysencks dimensional model of personality and gender. Personality and Individual Differences, 26(1), 5-11.

Fremont, J., \& Craighead, L. W. (1987). Aerobic exercise and cognitive therapy in the treatment of dysphoric moods. Cognitive Therapy and Research, 11(2), 241-251.

Gauvin, L., \& Spence, J. C. (1996). Physical activity and psychological well-being: Knowledge base, current issues, and caveats. Nutrition Reviews, 54(4), 53-65.

Gillham, J. E., \& Seligman, M. E. P. (1999). Footstep on the road to a positive psychology. Behaviour Research and Therapy, 37, 5163-5173.

Gregson, J. F., \& Colley, A. (1986). Concomitants of sport participation in male and female adolescents. International Journal of Sport Psychology, 17(1), 10-22.

Hassmen, P., Koivula, N., \& Uutela, A. (2000). Physical exercise and psychological well-being: A population study in Finland. Preventive Medicine, 30(1), 17-25. doi:10.1006/pmed.1999.0597

Headey, B., Muffels, R., \& Wagner, G. G. (2010). Longrunning German panel survey shows that personal and economic choices, not just genes, matter for happiness. Proceedings of the National Academy of Sciences, 107(42), 17922-17926. doi: 10.1073/pnas.1008612107

Hein, V. (2015). Parents' perceptions of the importance of physical activity and their children's ability. Baltic Journal of Sport \& Health Sciences, 4(99), 25-29.

Herman, K. M., Craig, C. L., Gauvin, L., \& Katzmarzyk, P. T. (2009). Tracking of obesity and physical activity from childhood to adulthood: The Physical Activity Longitudinal Study. International Journal of Pediatric Obesity, 4(4), 281-288.

Hills, P., \& Argyle, M. (2002). The Oxford Happiness Questionnaire: A compact scale for the measurement of psychological well-being. Personality and Individual Differences, 33(7), 1073-1082.

Holder, M. D., Coleman, B., \& Sehn, Z. L. (2009). The contribution of active and passive leisure to children's well-being. Journal of Health Psychology, 14(3), 378386. doi: 10.1177/1359105308101676

Huang, H., \& Humphreys, B. R. (2012). Sports participation and happiness: evidence from US microdata. Journal of Economic Psychology, 33(4), 776-793.
Kimm, S. Y., Glynn, N. W., Obarzanek, E., Kriska, A. M., Daniels, S. R., Barton, B. A., \& Liu, K. (2005). Relation between the changes in physical activity and body-mass index during adolescence: A multicentre longitudinal study. The Lancet, 366(9482), 301-307. https://dx.doi. org/10.1016/S0140-6736(05)66837-7

Kousha, M., \& Mohseni, N. (2000). Are Iranians happy? A comparative study between Iran and the United States. Social Indicators Research, 52(3), 259-289. doi: 10.1023/A:1007061431186

Lane, R. D., Reiman, E. M., Ahern, G. L., Schwartz, G. E., \& Davidson, R. J. (1997). Neuroanatomical correlates of happiness, sadness, and disgust. American Journal of Psychiatry, 154(7), 926-933.

Lijuan, W., Jiancui, S., \& Suzhe, Z. (2016). Parental influence on the physical activity of Chinese children: Do gender differences occur? European Physical Education Review, 1,1-18. doi: 10.1177/1356336X16641024

Lissitsa, S., Galily, Y., \& Chachashvili-Bololotin, S. (2010). Talking or acting? Gender differences in physical activity participation in Israel at the threshold of the 21st century. European Journal for Sport and Society, 7(1), 31-40.

Lyubomirsky, S., \& Lepper, H. S. (1999). A measure of subjective happiness: Preliminary reliability and construct validation. Social Indicators Research, 46(2), 137-155.

Mahon, N. E., Yarcheski, A., \& Yarcheski, T. J. (2005). Happiness as related to gender and health in early adolescents. Clinical Nursing Research, 14(2), 175-190. doi: 10.1177/1054773804271936

Marcus, B. H., \& Lewis, B. A. (2003). Physical activity and the stages of motivational readiness for change model. President's Council on Physical Fitness and Sports Research Digest, 4(1), 1-8.

McAuley, E., Blissmer, B., Marquez, D. X., Jerome, G. J., Kramer, A. F., \& Katula, J. (2000). Social relations, physical activity, and well-being in older adults. Preventive Medicine, 31(5), 608-617. https:// dx.doi.org/10.1006/pmed.2000.0740

Myers, D. G., \& Diener, E. (1995). Who is happy? Psychological Science, 6(1), 10-19.

Netz, Y., Wu, M. J., Becker, B. J., \& Tenenbaum, G. (2005). Physical activity and psychological well-being in advanced age: a meta-analysis of intervention studies. Psychology and Aging, 20(2), 272. https://dx.doi. org/10.1037/0882-7974.20.2.272

Oswald, A.J., \& Powdthavee, N. (2007). Obesity, unhappiness and the challenge of affluence: Theory and evidence. Economic Journal, 117(521), 441-454.

Ruseski, J. E., Humphreys, B. R., Hallman, K., Wicker, P., \& Breuer, C. (2014). Sport participation and subjective well-being: Instrumental variable results from German survey data. Journal of Physical Activity and Health, 11(2), 396-403. doi: 10.1123/jpah.2012-0001 
Seligman, M. E. P. (2003). Positive psychology: Fundamental assumptions. Psychologist, 16, 126-127.

Sin, N. L., \& Lyubomirsky, S. (2009). Enhancing well-being and alleviating depressive symptoms with positive psychology interventions: A practice-friendly meta-analysis. Journal of Clinical Psychology, 65(5), 467-487. doi: 10.1002/jclp.20593.

Seligman, M. E. P., \& Csikszentmihalyı, M. (2000). Positive Psychology: An Introduction. American Psychologist, 55(1), 5-14.

Stathi, A., Fox, K. R., \& McKenna, J. (2002). Physical activity and dimensions of subjective well-being in older adults. Journal of Aging and Physical Activity, 10, 76-92.

Stubbe, J. H., Boomsma, D. I., \& De Geus, E. J. (2005). Sports participation during adolescence: a shift from environmental to genetic factors. Medicine \& Science in Sports \& Exercise, 37(4), 563-570.

Stubbe, J. H., De Moor, M. H. M., Boomsma, D. I., \& De Geus, E. J. C. (2007). The association between exercise participation and well-being: A co-twin study.
Preventive Medicine, 44(2), 148-152. doi:10.1016/j. ypmed.2006.09.002

Taylor, C. B., Jatulis, D. E., Winkleby, M.A., Rockhill, B. J., \& Kraemer, H. C. (1994). Effects of life-style on body mass index change. Epidemiology, 5(6), 599-603.

Taylor, S. E., \& Brown, J. D. (1988). Illusion and wellbeing: A social psychological perspective on mental health. Psychological Bulletin, 103(2), 193.

Trost, S. G., Pate, R. R., Sallis, J. F., Freedson, P. S., Taylor, W. C., Dowda, M., \& Sirard, J. (2002). Age and gender differences in objectively measured physical activity in youth. Medicine and Science in Sports and Exercise, 34(2), 350-355. doi: 0195-9131/02/3402-0350 Weinberg, R. S., \& Gould, D. (2014). Foundations of Sport and Exercise Psychology, 6E. Human Kinetics.

Yalız Solmaz, D. (2014). The subjective well-being levels of teacher candidates: A research department of physical education and sports teaching at Anadolu University. The Journal of International Social Research, 7(35), 651-657. 